\title{
Comment
}

\section{Master in science communication: an overview}

\author{
Donato Ramani
}

\begin{abstract}
Science, politics, industry, media, state-run and private organisations, private citizens: everyone has their own demands, their own heritage of knowledge, thoughts, opinions, aspirations, needs. Different worlds that interact, question one another, discuss; in one word: they communicate. It is a complicated process that requires professionals "who clearly understand the key aspects of the transmission of scientific knowledge to society through the different essential communication channels for multiple organizations». The purpose of this commentary is to cast some light upon the goals, the philosophy and the organisation behind some European and extraEuropean Master's degrees in science communication. We have asked the directors of each of them to describe their founding elements, their origins, their specific features, their structure, their goals, the reasons why they were established and the evolution they have seen over their history.
\end{abstract}

Vladimir De Semir, director of the Master's degree in scientific, medical and environmental communication at Pompeu Fabra University, Barcelona, highlights in the first lines of his contribution to this commentary the importance of the current historical era, which sees a crucial passage, from the industrial society to the so-called society of knowledge. A society in which scientific and technological innovations are incorporated ever more quickly into our daily life. And in which investments in research and development become ever more crucial for the progress and the development of a country. Research and development in the technical and scientific field are and will become more and more crucial for the future of our economies, an economic and cultural revolution affecting society as a whole. It unavoidably needs to be more and more informed, to suitably cope with these changes, to grasp their potential, to assess their advantages and risks.

Science, politics, industry, media, state-run and private organisations, private citizens: there are many players on this stage, each having its own demands, its own heritage of knowledge, thoughts, opinions, aspirations, needs. Different worlds that interact, question one another, discuss; in one word: they communicate. So, this is the key word: communication. It is a process of radical change that, as De Semir wrote himself, requires professionals «who clearly understand the key aspects of the transmission of scientific knowledge to society through the different essential communication channels for multiple organizations». That is true, but where do they come from? Or, to put it in better words, who trains these professionals that evidently play (more or less consciously) such a significant role within society? Ever more frequently, science communication professionals do not come any longer from diverse backgrounds to subsequently become self-trained «on the field» with acquired skills renewed by experience. On the contrary, they now come from Master's degrees born and established in the most varied contexts: within prestigious research institutes devoted to mathematics, physics and neurosciences such as SISSA-ISAS, Trieste, or within specific departments devoted to communication, as it was the case with the experience of Dublin City University (DCU), established within the faculty of Social and Human Sciences. There are recently established Master's degrees, such as the MSC Science Communication at the Science Communication Unit, University of the West of England, Bristol, founded in 2004 or the Mestrado Multidisciplinar em Divulgação Científica e Cultural (MDCC) at the Universidade Estadual de Campinas, Brasile, established in early 2007. But there are also Master's degrees now having a well-established history, such as the Triestine or the Barcelona experiences, the latter having been exported over the Atlantic, to Buenos Aires, in 2008.

The purpose of this commentary it to cast some light upon the goals, the philosophy and the organisation behind these Master's degrees. We have asked the directors of each one of them to describe their founding elements, their origins, their specific features, their structure, their goals, the reasons why 
they were established and the evolution they have seen over their history. Through the words of the founders and of the organisers, we will take a glimpse of those paths that are adventures - even cultural ones - for students often having an extremely varied education. Practices and theories of communication placed side by side and becoming intertwined. As is the case in the Master's degree of Bristol, where, as the managers told us, aside from practical activities, «students cover a compulsory theoretical grounding in the module Science and Society, which explores shifts from traditional approaches to scientific literacy and public understanding to engagement and participation models». Or the case of DCU where, as Brien Trench writes, «the 'communication' in 'science communication' is understood as encompassing the relations between the organisations and institutions of science and those of society (including politics, education and media), and the perceptions that these communities have of each other. But 'communication' also covers the practices of information services, journalism, science centres and public relations, and students also take courses that address these subjects».

These are curricula that have to establish a close relation with the ever-changing world in which professionals will find themselves to act, shaping figures diffusely entering many contexts that should have suitable skills and a rich cultural heritage. In this context science communicators who work at the interface between science and society have a unique responsibility, as Vogt, Knobel and Toledo Camargo define it in their contribution. It is quite a crucial challenge, which requires the organisers and the schools themselves to have a considerable flexibility in the set-up and in the contents, a sensitiveness for ongoing changes and an inquisitive outlook on the relations between science and society. A challenge that has been taken on by all the schools mentioned here. We will see to what extent.

Translated by Massimo Caregnato

How TO CITE: D. Ramani, Master in science communication: an overview, Jcom 08(01) (2009) C01 